\title{
The mouse mammary tumor virus intasome exhibits distinct dynamics on target DNA
}

Laura E. Baltierra-Jasso ${ }^{1,2,3}$, Nathan D. Jones ${ }^{1}$, Allison Ballandras-Colas ${ }^{4}$, Alan N. Engelman ${ }^{5,6}$, Richard Fishel $^{1,2^{\star}}$ and Kristine E. Yoder ${ }^{1,2,3^{*}}$

${ }^{1}$ Department of Cancer Biology and Genetics, The Ohio State University College of Medicine, Columbus, Ohio, USA;

${ }^{2}$ Comprehensive Cancer Center, The Ohio State University

${ }^{3}$ Center for Retrovirus Research, The Ohio State University

${ }^{4}$ Institut de Biologie Structurale, Grenoble, France;

${ }^{5}$ Department of Cancer Immunology and Virology, Dana-Farber Cancer Institute, Boston, Massachusetts, USA;

${ }^{6}$ Department of Medicine, Harvard Medical School, Boston, Massachusetts, USA;

*To whom correspondence should be addressed. Tel: 01614688 2106; Email: yoder.176@osu.edu Correspondence may also be addressed to Richard Fishel. Email: rfishel@osu.edu

Present Address: Nathan D. Jones, Department of Biology, Johns Hopkins University, Baltimore, MD, 21287, USA

\begin{abstract}
Retroviral intasomes are complexes assembled from purified integrase (IN) and oligonucleotides mimicking viral DNA ends (vDNA). Recombinant intasomes faithfully recapitulate integration of vDNA into a target DNA. Structural studies of retroviral intasomes have revealed an array of IN oligomer forms, which appear to share a conserved intasome core coordinating the vDNA ends for strand transfer into the target DNA. Here we have explored the biochemical and dynamic properties of the mouse mammary tumor virus (MMTV) octameric intasome. We show that the MMTV intasome is remarkably stable compared to the prototype foamy virus (PFV) tetrameric intasome. MMTV integration activity peaks within the range of physiological ionic strength and is more active in the presence of manganese compared to magnesium. Single-molecule images demonstrate that the target DNA search by MMTV intasomes appears rate-limiting, similar to PFV intasomes. The time between strand transfer of the two MMTV vDNA ends into the target DNA is $\sim 3$ fold slower than PFV intasomes. MMTV intasomes can form extremely stable, largely immobile filaments on a target DNA that are comprised of multiple intasomes. This unusual property suggests that MMTV intasomes may readily form higher order oligomers that might underpin their increased stability.
\end{abstract}

\section{INTRODUCTION}


Retroviral RNA genomes are copied to linear double stranded DNA (cDNA) by reverse transcription (1). Integration of this cDNA into host chromatin is an essential step in the retroviral life cycle and is catalyzed by the viral protein integrase (IN) (1-3). During infection retroviral IN performs two catalytic activities. First, a 3' processing activity cleaves two terminal nucleotides from the cDNA 3' ends generating terminal recessed hydroxyl groups (3). Second, a strand transfer activity covalently joins the recessed 3' hydroxyls to host DNA (3-6). Depending on the retrovirus, the two strand transfer events are separated by 4-6 bp of host target DNA. The result is the integrated proviral genome flanked by 4-6 nt single strand gaps of host DNA and 5' dinucleotide flaps of viral cDNA. Host enzymes appear to repair this gapped integration intermediate resulting in a stable integrated provirus flanked by duplications of host DNA (7).

Retroviral INs have three common domains: an amino terminal domain (NTD), catalytic core domain (CCD), and carboxyl terminal domain (CTD) (reviewed in (3)). Some retroviruses, including the spumavirus prototype foamy virus (PFV), have an additional amino terminal extension domain (NED). The CCD includes a DDE catalytic triad that coordinates divalent metal cations. All domains participate in multimerization to form an integration complex. The linker region between the IN CCD and CTD varies in length between retroviruses and is predictive of the number of INs necessary for an active complex (8-12).

A multimer of retroviral IN binds the viral cDNA ends to form a functional enzymatic complex. This intasome may be assembled in vitro with recombinant IN and oligomers mimicking the viral cDNA ends (vDNA) (13). In addition, the vDNA may be labeled with small fluorophores or biotin moieties without affecting integration activity (14). The first retroviral intasome structures revealed a tetramer of PFV IN alone or bound to a target DNA $(13,15)$. The intasome-bound target DNA was distorted to accommodate strand transfer at 4 bp spacing across the major groove of host DNA (15). Two "inner" PFV IN subunits are catalytically active and bind both the vDNA and target DNA. Coordinates for only the CCD of the two "outer" PFV IN protomers have been resolved, which appear important for intasome structure but not catalysis (1518). Function(s) for the unresolved domains of the outer PFV IN protomers are unknown.

Intasome structures of orthoretroviruses showed a diversity of IN oligomerization (8,9,11$13,15,17,19)$. The deltaretrovirus human T cell leukemia virus (HTLV-1) intasome is also a tetramer of IN $(20,21)$. The alpharetrovirus Rous sarcoma virus (RSV) and the betaretrovirus mouse mammary tumor virus (MMTV) intasomes are octamers of IN $(8,9,12)$. The lentivirus Maedi visna virus (MVV) intasome is a hexadecamer of IN $(8,9,12)$. Tetramer and dodecamer HIV-1 IN architectures, as well as filaments of intasomes, were observed by single particle cryogenic electron microscopy $(11,22,23)$. All of these intasome structures notably display a conserved intasome core $(\mathrm{CIC})$ that is similar to the central structural elements of the PFV IN tetramer (24).

Retroviral integration in cells is inefficient, making interrogation of integration processes in vivo challenging (25-27). Real-time single-molecule imaging has been utilized to dissect the search and integration dynamics of PFV intasomes with target DNA in vitro $(18,28)$. These studies demonstrated a target DNA search for $2.1 \mathrm{~s}$ while in continuous contact with the DNA backbone, suggesting that PFV intasomes could interrogate $\sim 1.6 \mathrm{~kb}$ of duplex DNA, most likely by rotation coupled diffusion. Once an 
integration site was detected, the time between the two vDNA strand transfer events was $0.47 \mathrm{~s}(18,28,29)$. Remarkably, PFV intasomes performed 100-300 search events per strand transfer event strongly suggesting that target site selection was rate-limiting (28). To date, the dynamic interactions with target DNA have only been described for PFV intasomes $(18,28)$. Whether the CIC mediates similar kinetics with different oligomeric forms of IN protomers, similar to intasomes derived from highly pathogenic betaretroviruses and lentiviruses, is unclear.

While some retroviruses employ a host protein as an integration co-factor, none has been reported for MMTV (30-34). Retroviral integration host co-factors help determine the genomic integration profile relative to chromatin elements such as transcription units, promoters, or CpG islands (35-37). MMTV displays minimal preference for genomic elements, which agrees with the absence of an integration cofactor $(30,38,39)$. Despite this integration profile, the MMTV provirus is able to dysregulate cellular protooncogene expression leading to mammary adenocarcinomas in mice. Thus, MMTV infection has been employed as a model for breast cancer pathogenesis (31-33). Integration host co-factors are known to aid in the stability of recombinant intasomes, as in the case of the LEDGF/p75 host co-factor for lentiviruses MVV and HIV-1. However, PFV and MMTV intasomes may be readily assembled from recombinant IN and vDNA only $(8,9,11,15,40)$.

Here we have examined the biochemical properties, strand transfer kinetics, and search dynamics of the MMTV intasome. We found that these octameric intasomes display a longer time between the two strand transfer events and are capable of a prolonged search on target DNA compared to PFV intasomes. When multiple MMTV intasomes are present they appear to form filaments on the target DNA suggesting higher order interactions. These observations are consistent with the conclusion that retroviral intasomes display a common search mechanism with diverse search parameters.

\section{MATERIALS AND METHODS}

Chemicals. Chemicals were at least $98 \%$ pure and were purchased from Sigma-Aldrich, Millipore-Sigma, GoldBio, VWR and ThermoFisher. NHS ester Cy3 and Cy5 dyes were purchased from Lumiprobe. DNA oligonucleotides were synthesized by IDT (Newark, NJ).

MMTV integrase purification and labeling of viral DNA. The MMTV IN expression construct included an $\mathrm{N}$-terminal hexa-histidine tag, thrombin site, and human rhinovirus (HRV) $3 \mathrm{C}$ protease site. The protein was induced with $0.25 \mathrm{mM}$ IPTG in E.coli Rosetta BL21(DE3) (Novagen) in the presence of $50 \mu \mathrm{M} \mathrm{ZnCl}_{2}$ at $37^{\circ}$ C overnight. Bacteria were lysed in 20 mM HEPES (pH 7.5), $1 \mathrm{M} \mathrm{NaCl}, 5 \mathrm{mM}$ CHAPS and $1 \mathrm{mM}$ PMSF. Cells were sonicated and centrifuged at $120,000 \times \mathrm{g}$ for $1 \mathrm{~h}$ at $4^{\circ} \mathrm{C}$. The supernatant was applied to NiNTA Superflow resin (Qiagen) and proteins eluted with a gradient of 20-200 mM imidazole $(\mathrm{pH}$ 8.0). The histidine tag was removed by cleavage with HRV $3 \mathrm{C}$ protease overnight at $4^{\circ} \mathrm{C}$. MMTV IN was further purified with heparin sepharose (GE Healthcare). Pooled fractions were dialyzed in $20 \mathrm{mM} H E P E S$ (pH 7.5), $1 \mathrm{M} \mathrm{NaCl}, 5 \mathrm{mM}$ CHAPS, $2 \mathrm{mM}$ DTT, $0.5 \mathrm{mM}$ EDTA and $10 \%$ glycerol. Catalytically inactive MMTV 
IN(D122N) was prepared by the same purification method. Oligonucleotides of the transferred strand 5' CAGGT*CGGCCGACTGCGGCA 3' and non-transferred strand 5' AATGCCGCAGTCGGCCGACCTG 3' mimic the MMTV U5 end. $T^{*}$ indicates the position of a 4-amino-thymine used for conjugation of a Cy3 or Cy5 NHS ester. Labeled oligonucleotides were purified by HPLC Poroshell 120 EC-C18 reverse phase column (Agilent) and 12\% urea PAGE. The purified oligonucleotide was annealed to the non-transferred oligonucleotide yielding a preprocessed vDNA.

MMTV intasome assembly. Intasomes were assembled as previously described (8). Briefly, a 3:1 ratio of purified MMTV IN:vDNA in $20 \mathrm{mM}$ HEPES (pH 7.5), $600 \mathrm{mM} \mathrm{NaCl}, 2 \mathrm{mM}$ DTT was dialyzed overnight at $4^{\circ} \mathrm{C}$ against $25 \mathrm{mM}$ Tris- $\mathrm{HCl}$ (pH 7.5), $80 \mathrm{mM} \mathrm{NaCl}, 2 \mathrm{mM}$ DTT, $25 \mu \mathrm{M} \mathrm{ZnCl}_{2}, 10 \mathrm{mM} \mathrm{CaCl}$. The $\mathrm{NaCl}$ concentration was increased to $250 \mathrm{mM}$ and incubated $1 \mathrm{~h}$ on ice. Intasomes were purified by size exclusion chromatography with a Superdex 200 Increase (10/300) column (GE Healthcare) equilibrated in $25 \mathrm{mM}$ Tris- $\mathrm{HCl}$ (pH 7.5), $200 \mathrm{mM} \mathrm{NaCl}, 2 \mathrm{mM}$ DTT, $25 \mu \mathrm{M} \mathrm{ZnCl}_{2}, 10 \mathrm{mM} \mathrm{CaCl}_{2}$ and $10 \%$ glycerol. Individual fractions were frozen with liquid nitrogen and stored at $-80^{\circ} \mathrm{C}$. Frozen MMTV intasomes retained activity for at least 6 months.

Integration assays. Integration reactions were $20 \mathrm{mM}$ HEPES ( $\mathrm{pH}$ 7.5), $110 \mathrm{mM} \mathrm{NaCl}, 4 \mu \mathrm{M} \mathrm{ZnCl} 2,10$ mM DTT, $20 \mathrm{mM} \mathrm{MgSO}_{4}, 1.8 \mathrm{nM} 3 \mathrm{~kb}$ supercoiled pGEMT plasmid (Promega), and $20 \mathrm{nM}$ MMTV intasomes in a final volume of $15 \mu \mathrm{L}$. Excluding kinetic assays, all integration reactions were incubated for $1 \mathrm{~h}$ at $37^{\circ}$ C. Reactions were stopped with the addition of $0.5 \% \mathrm{SDS}, 0.5 \mathrm{mg} / \mathrm{mL}$ proteinase $\mathrm{K}, 25 \mathrm{mM}$ EDTA (pH 8.0) and incubated for $1 \mathrm{~h}$ at $37^{\circ} \mathrm{C} .18 \mathrm{fmol}$ of a $717 \mathrm{bp}$ linear DNA was added to some reactions as a gel loading control. Integration products were resolved by $1.25 \%$ agarose gel electrophoresis, stained with ethidium bromide and scanned for Cy5 and ethidium bromide fluorescence (Sapphire Biomolecular Imager, Azure Biosystems). Images were quantified with GelAnalyzer software (Azure Biosystems). Cy5 fluorescent products include unreacted vDNA, concerted integration $\left(\mathrm{Cl}^{1}\right)$ of both vDNA resulting in linear products, and half site integration ( $\mathrm{HSI}$ ) of a single vDNA to the target DNA yielding a relaxed circle. Ethidium bromide images visualize the unreacted supercoiled target DNA, linear and relaxed plasmid DNA, and the loading control. Multiple $\mathrm{Cl}$ events to a single supercoiled target DNA resulted in a Cy5 smear ( $\mathrm{Cl}^{2}$ products). The $\mathrm{Cl}^{2}$ products were included in the calculation of total $\mathrm{Cl}\left(\mathrm{Cl}=\mathrm{Cl}^{1}+\mathrm{Cl}^{2}\right)$ as previously described (29). All experiments were performed in triplicate with at least two independent preparations of MMTV intasomes. Statistical significance of integration reactions was determined by paired $t$ test to generate two-tail $P$ values (Excel).

Aggregation assays. $20 \mathrm{nM}$ MMTV intasomes were incubated in $20 \mathrm{mM} \mathrm{HEPES}(\mathrm{pH}$ 7.5), $110 \mathrm{mM} \mathrm{NaCl}$, $4 \mu \mathrm{M} \mathrm{ZnCl} 2,10 \mathrm{mM} \mathrm{DTT}, 20 \mathrm{mM} \mathrm{MgSO}_{4}$, except where noted, for $1 \mathrm{~h}$ at $37^{\circ} \mathrm{C}$ in $100 \mu \mathrm{L}$ total volume. Where indicated, $1.8 \mathrm{nM}$ linear $3 \mathrm{~kb}$ DNA was included. Samples were centrifuged at 18,000 $\mathrm{g} \mathrm{g}$ for $30 \mathrm{~min}$ at $4^{\circ} \mathrm{C}$. Pellets were resuspended in denaturing PAGE buffer and resolved by $12 \%$ PAGE. Gels were 
stained with Coomassie Brilliant Blue, scanned (Sapphire Biomolecular Imager, Azure Biosystems), and quantified (GelAnalyzer software, Azure Biosystems). Band intensities were normalized to the sample without $\mathrm{MgSO}_{4}$ or the sample with the lowest concentration of $\mathrm{NaCl}$. Statistical significance of aggregation reactions was determined by paired $t$ test to generate two-tail $P$ values (Microsoft Excel).

Single-molecule magnetic tweezers. Single-molecule magnetic tweezers analysis was performed as previously described $(28,29)$. Briefly, a $7 \mathrm{~kb}$ DNA substrate was generated by ligating a linker with multiple biotins to one end and a linker with multiple digoxygenins to the other end. Glass slides were treated with 3-aminopropyl triethoxysilane and passivated with a biotin-PEG SVA/mPEG SVA mix (Invitrogen). Treated glass slides were assembled with double sided tape and an aluminum backing to generate flow channels in a custom microscope slide. The DNA substrate was tethered to the surface via NeutrAvidin (Invitrogen). Paramagnetic beads (Thermo Fisher Scientific) coated with anti-digoxygenin (Novus Biologicals) were injected into the channel. Ten negative supercoils were induced by an equivalent number of counterclockwise turns of a neodymium magnet above the flow cell slide at $0.3 \mathrm{pN}$ force. Reactions containing 20 nM MMTV intasomes in 30 mM Bis-tris propane (pH 7.5), $110 \mathrm{mM} \mathrm{NaCl}, 4 \mu \mathrm{M} \mathrm{ZnCl}, 250 \mu \mathrm{M}$ DTT, $20 \mathrm{mM}$ $\mathrm{MgSO}_{4}, 200 \mu \mathrm{g} / \mathrm{mL}$ acetylated BSA, $0.02 \%$ IGEPAL were flowed into the channel. Movies were recorded for $30 \mathrm{~min}$ at a $100 \mathrm{~ms}$ frame rate. The $3 \mathrm{D}$ positions of the paramagnetic beads were evaluated using the tracking software Video Spot Tracker (CISMM at UNC-CH). Resultant coordinates were analyzed using custom MATLAB scripts (MathWorks). The time between the two strand transfer events ( $\tau_{S T}$ ) was determined for concerted integration events; the initial change in the z-position corresponded to the first strand transfer and subsequent movement in all axes ( $x-, y-$ and $z-)$ indicated the second strand transfer. Histograms generated from $n$ events were fit as a single exponential decay to determine the mean $\tau_{S T}$ and standard error (Origin, OriginLabs). Binning of histograms was performed as described previously with a bin minimum of $100 \mathrm{~ms}(28,41,42)$.

Single-molecule total internal reflection fluorescence. Single-molecule total internal reflection fluorescence (smTIRF) was performed as previously described (28). Briefly, phage $\lambda$ DNA was digested with restriction endonuclease XmaJl to generate $24 \mathrm{~kb}$ fragment DNAs. Biotin labeled DNA linkers were ligated to the fragment ends. Flow cells were assembled from quartz slides treated with 1 biotin-PEGSVA:300 mPEG-SVA and glass cover slips treated with mPEG-SVA. NeutrAvidin was injected into the flow cell followed by addition of biotinylated $\lambda$ fragments stretched by flow.

Imaging was performed with 50-100 pM or 2 nM MMTV intasomes with Cy5 or Cy3 labeled vDNA in $30 \mathrm{mM}$ Bis-tris propane ( $\mathrm{pH}$ 7.5), $110 \mathrm{mM} \mathrm{NaCl}, 20 \mathrm{mM} \mathrm{MgSO}_{4}, 4 \mu \mathrm{M} \mathrm{ZnCl}_{2}, 100 \mu \mathrm{M}$ DTT, $200 \mu \mathrm{g} / \mathrm{mL}$ acetylated BSA, $0.02 \%$ IGEPAL, $20 \mathrm{nM}$ protocatechuate 3,4-dioxygenase (PCD), and $5 \mathrm{mM}$ protocatechuic acid. PCD was prepared as described $(43,44)$. Fluorescence was detected with a custom built prism TIRF microscope (Olympus IX-71, water-type 60X objective NA $=1.2,1.6 \mathrm{X}$ extended magnification) and recorded on an electron-multiplying charge-coupled device camera (EMCCD, Princeton Instruments, 
ProEM 512 excelon). Lifetime and diffusion were recorded for $1200 \mathrm{~s}$ at a $250 \mathrm{~ms}$ frame rate. Following the real-time recordings, the target DNA was stained with Syto 59 Red Fluorescent Nucleic Acid Stain (Thermo Fisher Scientific) and the images overlaid onto the Cy5 or Cy3 movies. Particles were tracked using DiaTrack software (Sydney, Australia) and the results were analyzed with MATLAB (MathWorks) and Origin Pro (OriginLab) (45).

\section{RESULTS}

\section{Purified MMTV intasomes catalyze concerted integration}

Recombinant MMTV intasomes were assembled with Cy5 labeled vDNA $(8,9,13,15,17)$. Size exclusion chromatography (SEC) revealed a high molecular weight peak (530 kDa) consistent with an asymmetric octamer of MMTV IN and two vDNAs (Supplementary Figure S1A). Two additional peaks were also observed, consistent with a dimer of MMTV IN (100 kDa) and free VDNA (19 kDa).

MMTV intasome SEC fractions were analyzed for integration activity by agarose gel electrophoresis. Concerted integration $\left(\mathrm{Cl}^{1}\right)$ of the two vDNAs to a supercoiled (SC) plasmid results in a linear product (LN) (Supplementary Figure S1B). Additional concerted integration (Cl) into the linear $\mathrm{Cl}^{1}$ product may produce an array of shortened linear products $\left(\mathrm{Cl}^{2}\right)$. Intasomes may also integrate a single vDNA to the target plasmid, termed half site integration ( $\mathrm{HSI}$ ), appearing as a product with the mobility of a relaxed circle $(R C)$. Gels were visualized by ethidium bromide staining of DNA and Cy5 fluorescence of vDNA and integration products (Supplementary Figure S1C, D). Analysis of SEC fractions indicated that the octameric MMTV intasome was active, which can be easily observed by the generation of Cy5 fluorescent $\mathrm{Cl}^{1}$ and $\mathrm{Cl}^{2}$ products.

Divalent cations are required for the assembly and catalytic activities of retroviral integration complexes (46-48). HIV-1 IN is catalytically active in the presence of magnesium or manganese, but is not active in the presence of calcium $(46,48,49)$. This observation provided the foundation for the purification of intasomes in the presence of calcium, effectively preventing catalysis until the addition of magnesium or manganese $(8,50)$.

The effects of magnesium and manganese on MMTV intasome integration activity were examined in reactions that included $1 \mathrm{mM} \mathrm{CaCl} 2$ which was carried over from the SEC purification buffer. Cy5 labeled $\mathrm{Cl}^{1}$ products were observed beginning at a 2 fold molar excess of $\mathrm{MgCl}_{2}$ to $\mathrm{CaCl}_{2}$, with $\mathrm{Cl}^{1}$ products continuing to increase up to the maximum of 15 fold molar excess used in these experiments (Figure $1 \mathrm{~A}$, Supplementary Figure $\mathrm{S} 2 \mathrm{~A}$ ). At $10 \mathrm{mM} \mathrm{MgCl} 2$ we observed the accumulation of $\mathrm{Cl}^{2}$ products. Autointegration $(\mathrm{Al})$ products are the result of one vDNA integrating to a second vDNA. Al products were observed in the presence of $15 \mathrm{mM} \mathrm{MgCl}_{2}$. In the presence of $1 \mathrm{mM} \mathrm{MnCl}_{2}$ we observed $\mathrm{Cl}^{1}, \mathrm{Cl}^{2}$ and $\mathrm{HSI}$ products. (Figure 1B, Supplementary Figure S2B). The increased integration activity in the presence of $\mathrm{MnCl}_{2}$ likely reflects an enhanced ability of manganese ions to displace calcium ions, similar to previous studies with isocitrate dehydrogenase and chelators such as EGTA (51). However, $\mathrm{MnCl}_{2}$ also substantially increased the fraction of Al products, which could potentially complicate biochemical and kinetic analysis. 
In addition, we have found that manganese is incompatible with the oxygen scavenging system (OSS) that is essential for single-molecule imaging analysis. Equivalent concentrations of $\mathrm{MgSO}_{4}$ yielded approximately $30 \%$ less $\mathrm{Cl}$ products compared to $\mathrm{MgCl}_{2}$ (Figure $1 \mathrm{C}$, Supplementary Figure S2C). However, $\mathrm{MgSO}_{4}$ resulted in virtually undetectable $\mathrm{Al}$ products and was used in subsequent reactions. The biochemical cause(s) of the chloride versus sulfate anion dissimilarity in MMTV integration is unknown.

\section{MMTV intasomes function best at physiologically relevant ionic strength}

The integration activity of MMTV intasomes was assessed over a range of $\mathrm{NaCl}$ concentrations (Figure 1D, Supplementary Figure S2D). The formation of Cl products peaked at $150 \mathrm{mM} \mathrm{NaCl}$ and appeared to rapidly decrease to nearly undetectable at $300 \mathrm{mM} \mathrm{NaCl}$. We conclude that that the maximal MMTV activity occurs within the physiological range of ionic strength. All subsequent biochemical, kinetic and single-molecule studies of MMTV intasome activity were performed in $110 \mathrm{mM} \mathrm{NaCl}$, in a final reaction buffer composition similar to physiological ionic strength.

\section{MMTV intasome integration displays saturation kinetics}

MMTV intasome integration to a SC plasmid target DNA was measured over time. MMTV intasomes generated $\mathrm{Cl}$ products for at least 80 min with product saturation occurring when only $50-60 \%$ of the target SC plasmid remained (Figure 2A; Supplementary Figure S2E). In contrast, HSI products reached a plateau after $5 \mathrm{~min}$ and remained at $\sim 10 \%$ of the total integration products. These results appear consistent with the conclusion that $\mathrm{HSI}$ mostly results from a fraction of defective intasomes rather than a kinetically separable intermediate that progresses to a $\mathrm{Cl}$ product.

Because the integration reaction kinetics were linear when the $\mathrm{Cl}$ products were below $20 \mathrm{fmol}$ we performed a Michealis-Menten substrate concentration analysis (Figure 2B). Sequencing of integration sites in genomic DNA indicated that MMTV has no apparent DNA sequence preference (39). Structural studies have suggested that the MMTV intasome may occupy a 6-12 bp footprint (8). Together these observations suggest an $\sim 30$ fold excess of target sites at these integration assay conditions. Moreover, retroviral intasomes do not turn over. As might be expected, we found that the MMTV intasome substratedependent kinetic data fit extremely well to saturable enzymes with a deceleration component at elevated substrate concentration resulting from the lack of enzyme turnover (52) (Figure 2B). We calculated an apparent $k_{\text {cat } a p p}\left(0.01 \mathrm{~min}^{-1}\right)$ that reflects the bulk enzyme rate of integration catalysis (Figure $2 \mathrm{~B}$ ). Because the occupied site size is not precisely known we could only calculate a range for the $K_{m \cdot a p p}(34.5-69.0 \mathrm{nM})$. These results echo previous studies that have suggested retroviral integration is inefficient $(25,27)$. Since an infected cell is likely to harbor a single integration complex capable of catalyzing integration, the cellular concentration will be well below nM suggesting that successful target site identification will be limiting (28).

\section{MMTV intasome aggregation can be reduced by altering solvent components}


Purified PFV intasomes appear to readily aggregate in solution resulting in substantial loss of integration activity (29). This aggregation at least partly explains the lack of PFV integration activity after 5 min at $37^{\circ}$ C. Single-molecule total internal reflection fluorescence (smTIRF) imaging employs an OSS to reduce photobleaching of fluorophores by reactive oxygen species (ROS) $(43,44,53)$. Protocatechuate $3,4-$ dioxygenase (PCD) uses protocatechuic acid (PCA) as a substrate to effectively scavenge free oxygen, which contributes to ROS-induced photobleaching. Interestingly, PCA prevented aggregation of PFV intasomes and enhanced integration efficiency (29). Acetylated bovine serum albumen (BSA) also enhanced PFV integration efficiency, presumably by stabilizing the PFV intasome similar to other enzymes in solution $(54,55)$.

We evaluated the effects of PCA and acetylated BSA on MMTV integration and found that neither significantly enhanced MMTV integration when included as a buffer component (Supplemental Figure S3). Moreover, elevated concentrations of PCA appeared to reduce MMTV intasome $\mathrm{Cl}$ activity, though this difference did not reach statistical significance. We also determined that pre-incubation of MMTV intasomes with acetylated BSA for 30 min at $37^{\circ} \mathrm{C}$ before the addition of target DNA did not significantly increase integration efficiency, consistent with little or no stabilization of the intasomes (data not shown).

We evaluated the aggregation of MMTV intasomes in reactions that included $\mathrm{CaCl}_{2}(1 \mathrm{mM})$ carried over from the purification. This analysis relied on centrifugal precipitation of high molecular weight aggregates. We compared the relative quantity of precipitated aggregates in the absence or presence of additives. A significant reduction in aggregation was observed with the addition of acetylated BSA (47\%, $p$ $=0.003$; Figure $3 \mathrm{~A}$, lane 7 compared to lane 1). This result parallels studies with PFV intasomes and suggests acetylated BSA fundamentally alters MMTV intasome solvation (29,54,55). MMTV intasome aggregation was reduced by $34 \%$ with additional $\mathrm{CaCl}_{2}(10 \mathrm{mM}, \mathrm{p}=0.008$; Figure $3 \mathrm{~A})$. $\mathrm{MgSO}_{4}$ also reduced the aggregation of MMTV intasomes by $29 \%(20 \mathrm{mM}, \mathrm{p}=0.05)$. Elevated $\mathrm{NaCl}$ concentrations similarly reduced MMTV intasome aggregation (Figure 3B). However, MMTV intasome integration activity peaked at physiological monovalent salt concentrations (100-150 mM NaCl, Figure 1D) despite the relatively higher aggregation. It is notable that the prevention of MMTV intasome aggregation at the higher $\mathrm{NaCl}$ concentrations was similar to that achieved in the presence of $0.2 \mu \mathrm{g} / \mathrm{ml}$ acetylated BSA.

\section{Octameric MMTV intasomes display slower strand transfer kinetics and DNA diffusion than tetrameric PFV intasomes}

Retroviral intasomes covalently join each end of the viral cDNA to the host DNA via two independent strand transfer reactions. Single-molecule magnetic tweezers (smMT) analysis was utilized to determine the realtime strand transfer kinetics of MMTV intasomes. In this system a target DNA is tethered at one end to a passivated flow-cell surface by multiple contact points along the backbones of both DNA strands, while the second end is tethered by multiple contact points also along the backbones of both DNA strands to a paramagnetic bead (PMB) (28). Counter-clockwise turns of a neodymium magnet at low magnetic field force $(0.3 \mathrm{pN})$ induced negative supercoils which are a preferred substrate for MMTV intasomes. The time 
between the two intasome-catalyzed strand transfers ( $\tau$ ST) may be distinguished with smMT by tracking the vertical and horizontal motions of individual PMBs (Figure 4A; Supplementary Figure S4A). The first strand transfer is visualized as the PMB position changes on the z-axis when the MMTV intasome has nicked the DNA releasing the negative supercoils. The second strand transfer is observed when the intasome nicks the second DNA strand leading to a double strand break and the PMB position is altered in all axes. MMTV intasomes displayed a $\tau_{\mathrm{ST} \cdot \mathrm{MMTV}}$ that was nearly 3 fold longer than the $\tau$ ST.PFV reported for PFV intasomes (Figure 4B, $\quad \tau_{\mathrm{ST} \cdot \mathrm{MMTV}}=1.31 \pm 0.12 \mathrm{~s} ; \tau_{\mathrm{ST} \cdot \mathrm{PFV}}=0.47 \pm 0.05 \mathrm{~s}$; mean $\pm \mathrm{s} . \mathrm{e}$.) $(28)$. Moreover, the maximum time observed between MMTV intasome strand transfers was $8 \mathrm{~s}(\mathrm{~N}=41)$, while the maximum time observed for PFV intasome strand transfers was $2.5 \mathrm{~s}(\mathrm{~N}=38)$. The relaxation time $\left(\tau_{\mathrm{RE}}\right)$ that measures the release of the supercoils from the target DNA following the first strand transfer was extracted from the integration data (Supplementary Figure S4B, $0.21 \pm 0.01 \mathrm{~s}$ ), which is similar to previous results with the PFV intasome as well as nickase-induced supercoil relaxation (28). These results are consistent with the conclusion that the strand transfer kinetics of MMTV intasomes are intrinsically slower than PFV intasomes, but this difference is not a result of MMTV intasome interference with the fundamental kinetics of DNA supercoil relaxation. These studies are unable to distinguish whether the longer MMTV strand transfer time is a result of the larger octameric intasome, the longer distance between strand transfer sites on the target DNA ( 6 bp for MMTV versus 4 bp for PFV), or some other unknown catalytic factors.

Previous studies with PFV intasomes suggested that the rate-limiting step for integration was the DNA search process (28). We used real-time smTIRF microscopy to visualize single MMTV intasomes on a $24 \mathrm{~kb} \lambda$-based target DNA, as previously described (28). Numerous single particles were observed moving along the DNA (Figure 4C; Supplementary Figure S5A; Supplementary Movies 1-4). The lifetime of the MMTV intasome-DNA interaction decreased with increasing salt concentration consistent with increasing ionic shielding of the DNA backbone from protein binding activity (Figure 4D; Supplementary Figure S5B, S6A-D). Within the physiological ionic window, the lifetime of MMTV intasomes on the target DNA appeared to be $4.6 \pm 0.6 \mathrm{~s}$, approximately twice as long as PFV intasomes $(2.1 \pm 0.1 \mathrm{~s})(28)$.

The diffusion coefficient of MMTV intasome particles on the DNA (DммтV $=0.035 \pm 0.02 \mu \mathrm{m}^{2} / \mathrm{s}, 110$ $\mathrm{mM} \mathrm{NaCl}$ ) was approximately 2 fold slower than PFV intasomes (DPFV $=0.082 \pm 0.005 \mu \mathrm{m}^{2} / \mathrm{s}, 110 \mathrm{mM}$ $\mathrm{NaCl}$ ) (28). These observations are consistent with an increased Stokes' drag associated with the larger octameric size of MMTV intasomes compared to the tetrameric PFV intasomes. We determined that the diffusion coefficient was constant over a range of ionic strength, consistent with the conclusion that the MMTV intasome maintains continuous contact with the DNA backbone (Figure 4E; Supplementary Figure $\mathrm{S5B})$. Unfortunately, there is currently no structure of the MMTV intasome bound to a target DNA, which is minimally required to calculate a rough landscape diffusion free-energy barrier that might suggest a possible rotation-coupled diffusion mechanism along the DNA (56,57). Nevertheless, the diffusion coefficient indicates that the MMTV intasome may interact with approximately $2.5 \mathrm{~kb}$ of target DNA during an average $4.60 \pm 0.57 \mathrm{~s}$ lifetime in $110 \mathrm{mM} \mathrm{NaCl}$, most likely in a rotation-coupled site-search capacity. We did not 
observe any concerted integration events during 322 searches of smTIRF target DNA. The lack of efficient integration into a linear target DNA is typical for retroviral intasomes (28).

Catalytically inactive intasomes were assembled with the point mutant MMTV IN(D122N) and Cy5 labeled vDNA. These inactive MMTV intasomes displayed a similar lifetime (4.71 $\pm 0.33 \mathrm{~s})$ and diffusion coefficient $\left(0.033 \pm 0.02 \mu \mathrm{m}^{2} / \mathrm{s}\right)$ to wild type MMTV intasomes (Supplementary Figure S5C,D, S6E). These results are consistent with the conclusion that catalysis of strand transfer is independent of DNA binding and diffusion along the target DNA backbone (28).

\section{MMTV intasomes form filaments on target DNA}

At low MMTV intasome concentrations single particles may be observed interacting with and diffusing along a target DNA by smTIRF. However, when the MMTV intasome concentration is increased, particles appear to aggregate and ultimately form nucleoprotein filaments along the entire length of the $24 \mathrm{~kb}$ duplex target DNA (Figure 5A). Moreover, at the initiation of these aggregates there is no visible motion of the intasomes along the DNA. Importantly, we observed little if any integration events that would result in DNA breakage and segregation of the two halves into visible globular aggregates (Figure 5A). We examined the stability of these aggregates by centrifugal precipitation analysis. Intasomes reconstituted with wild type IN or IN(D122N) appeared significantly more prone to precipitation in the presence of linear DNA (Figure 5B). Together these observations suggest that MMTV intasomes may spontaneously form stable aggregates that progress to nucleoprotein filaments when in proximity on target DNA.

\section{DISCUSSION}

The tetrameric PFV intasome was the first high resolution retroviral intasome structure described and has served as a model for studies of intasome mediated integration $(13,15)$. Two catalytically active inner PFV IN protomers were shown to position the vDNA ends near a target DNA, while the outer two IN protomers were not completely resolved but appear to play structural roles in stability of the complex $(13,15)$. Several other retroviral intasome structures have been visualized in recent years revealing a spectrum of IN multimers $(8,9,11-13,15,17,20,21)$. A common feature of all these intasome multimers is a $\mathrm{CIC}$ (24). The roles of additional IN protomers outside the CIC are largely unknown.

Here we characterized the activity of octameric MMTV intasomes under a variety of biochemical conditions. Importantly, calcium cations are essential for the assembly of stable intasomes because they stabilize the IN-vDNA interaction but are incapable of acting as a cofactor during strand transfer $(8,46)$. These calcium cations must be displaced by magnesium or manganese that can serve as metal ion cofactors capable of coordinating the $S_{N} 2$ nucleophilic integration reaction (58). We noted a significant increase in bulk integration products in the presence of the manganese cation (Figure 1). Manganese cations have been shown to alter the catalytic activity of the transposase from bacterial transposon Tn10, while HIV-1 IN displays equivalent activity in magnesium or manganese $(46,48,49,59)$. Similarly, PFV displays equivalent strand transfer activity in both divalent cations, but exhibits increased 3'-end processing 
in the presence of manganese (47). Since the MMTV intasomes were assembled with oligomers that mimic the 3'-end processed vDNA the increased integration activity with manganese cannot result from enhanced 3'-end processing but rather improved strand transfer. Consistent with this conclusion, manganese also led to increased Al products that can only be formed by strand transfer. Manganese cations display a more relaxed catalytic coordination that may facilitate end-to-end joining of vDNA, non-specific DNA endonuclease activity, and/or non-specific alcoholysis (60-62). However, we regard it more likely that the enhanced catalytic activity exhibited by the manganese cation reflects its ability to displace calcium from the catalytic active site similar to other enzymes (51). These observations highlight the unique behavior of different retroviral IN enzymes to variably employ different divalent cations.

Detailed dynamic processes of PFV intasome association and integration into a target DNA have been visualized by SmTIRF and smMT techniques. These previous studies suggested that the PFV intasome binds and moves along a linear target DNA for $2.1 \mathrm{sec}$ by rotation-coupled diffusion (28). Together with an observed diffusion coefficient of $0.08 \mu \mathrm{m}^{2} / \mathrm{sec}$, it was calculated that PFV intasomes interrogate $\sim 1.6 \mathrm{~kb}$ of DNA during every binding event (28). Remarkably, only one of every 100-300 binding events resulted in integration (28). Nevertheless, once an integration site was identified, the time between sequential strand transfer events was $0.47 \mathrm{~s}$ on average (28).

Interestingly, the time between MMTV intasome strand transfer events $(1.31 \mathrm{~s})$ was $\sim 3$ fold slower than PFV intasomes. The slower strand transfer kinetics may reflect an intrinsically slower strand transfer chemistry or the relatively increased distance between the strand transfer joining points (4 bp for PFV and $6 \mathrm{bp}$ for MMTV), among other possibilities (63). The average lifetime of MMTV intasomes on the DNA (4.6 s) was longer than PFV intasomes. Taken together these observations suggest that MMTV intasomes are catalytically less efficient than PFV intasomes. This conclusion is further mirrored by bulk integration kinetic analysis (Figure 2) that suggested a very slow $k_{\text {cat app }}\left(0.01 \mathrm{~min}^{-1}\right)$ for MMTV integration catalysis and relatively high $K_{m \cdot a p p}(34.5-69.0 \mathrm{nM})$.

Multiple mechanisms have been described for molecular searches of DNA (64-70). An ionic strength-independent diffusion was observed for both MMTV intasomes and PFV intasomes in agreement with one common search mechanism (28). As might be expected, the diffusion of the octameric MMTV intasome on a target DNA (DммтV $=0.035 \pm 0.02 \mu \mathrm{m}^{2} / \mathrm{s}$ ) was significantly slower than the tetrameric PFV $\left(\mathrm{DPFV}=0.082 \pm 0.005 \mu \mathrm{m}^{2} / \mathrm{s}\right)$. In the absence of a structure with the MMTV intasome bound to target DNA, it is impossible to calculate the rough landscape diffusion constants that would strengthen a rotationcoupled diffusion search model. However, the data is consistent with a model of 1D diffusion in continuous contact with the target DNA (64).

The combination of 1D and 3D mechanisms enhance DNA site search efficiency. Rotation-coupled 1D facilitated diffusion has been observed for the Type II restriction endonuclease EcoRV, which is also able to perform 3D dissociation/reassociation searching $(71,72)$. The single-molecule imaging approaches presented here are unable to determine a role of 3D searching during retroviral intasome interaction with target DNA. Studies of HIV-1 IN predating intasome purification methods suggested a quick commitment 
to target DNA suggesting that this retroviral IN is incapable of 3D searching (73). However, similar experiments with recombinant PFV IN showed it to be more promiscuous for target DNA, supporting a hypothesis that retroviruses may employ multiple target search mechanisms (47).

There is no known host co-factor for either PFV or MMTV intasomes, unlike lentiviral intasomes that require LEDGF/p75 $(8,9,11,74)$. During infection, PFV and MMTV integration profiles suggest that there is little to no preference for genomic features, such as transcription units or promoters $(17,30,37,75,76)$. This information offers little insight as to how PFV or MMTV intasomes find a target site in vivo. Host cofactors, such as LEDGF/p75, that include chromatin and DNA binding domains may dramatically alter the search mechanisms of intasomes. Thus, the influence of a host co-factor search mechanism on intasome search dynamics remains to be explored.

Finally, we have found that increasing the concentration of MMTV intasomes results in the formation of stable aggregates and filaments on the target DNA (Figure 5). We note that HIV-1 preintegration complexes have been observed to merge and form clusters in the nuclei of primary monocyte derived macrophages (77). Moreover, HIV-1 intasomes that appear to consist of at least a dodecamer of IN subunits also form filaments in solution in the absence of a target DNA (22). This type of aggregation activity suggests that IN associations outside the CIC may reflect both specific and non-specific interactions. It is notable that MMTV intasomes resemble PFV intasomes in DNA search mechanics, strand transfer kinetics, lack of a requisite host co-factor, and ease of recombinant intasome reconstitution. Alternatively, MMTV integration complexes more closely resemble HIV-1 integration complexes in IN multimerization beyond the $\mathrm{CIC}$ as well as aggregate/filament formation. These observations appear to suggest that that the MMTV intasome occupies an assembly and catalytic median between the intasomes of PFV and HIV1. It is likely that comparison of PFV, MMTV, and HIV-1 intasome dynamics will help to parse the mechanical processes that define integration for distinct retrovirus species.

\section{AVAILABILITY}

Video Spot Tracker is available in the GitHub repository (https://github.com/CISMM/video). DiaTrack software is available for download (http://www.diatrack.org/contact.html).

\section{SUPPLEMENTARY DATA}

Supplementary data are available at NAR online.

\section{FUNDING}

This work was supported in part by the The Ohio State University Comprehensive Cancer Center Pelotonia Fellowship Program (LEBJ). Any opinions, findings, and conclusions expressed in this material are those of the author(s) and do not necessarily reflect those of the Pelotonia Fellowship Program or OSU. This work was also supported by NIH grants Al126742 (KEY and RF) and AI070042 (ANE). 
Conflict of interest statement. ANE has been compensated by ViiV Healthcare Co for consultation unrelated to this work. No other authors have anything to declare.

\section{REFERENCES}

1. (1997) Retroviruses. Cold Spring Harbor Laboratory Press, Cold Spring Harbor (NY).

2. Brown, P.O. (1990) Integration of Retroviral DNA. Springer, Berlin, Heidelberg.

3. Engelman, A. and Cherepanov, P. (2014) Retroviral Integrase Structure and DNA Recombination Mechanism. Microbiol Spectr, 2, 1-22.

4. Li, M. and Craigie, R. (2005) Processing of viral DNA ends channels the HIV-1 integration reaction to concerted integration. J. Biol. Chem., 280, 29334-29339.

5. Li, M., Mizuuchi, M., Burke, T.R. and Craigie, R. (2006) Retroviral DNA integration: reaction pathway and critical intermediates. EMBO J., 25, 1295-1304.

6. Roth, M.J., Schwartzberg, P.L. and Goff, S.P. (1989) Structure of the termini of DNA intermediates in the integration of retroviral DNA: dependence on IN function and terminal DNA sequence. Cell, 58, 47-54.

7. Yoder, K.E. and Bushman, F.D. (2000) Repair of gaps in retroviral DNA integration intermediates. Journal of Virology, 74, 11191-11200.

8. Ballandras-Colas, A., Brown, M., Cook, N.J., Dewdney, T.G., Demeler, B., Cherepanov, P., Lyumkis, D. and Engelman, A.N. (2016) Cryo-EM reveals a novel octameric integrase structure for betaretroviral intasome function. Nature, 530, 358-361.

9. Ballandras-Colas, A., Maskell, D.P., Serrao, E., Locke, J., Swuec, P., Jónsson, S.R., Kotecha, A., Cook, N.J., Pye, V.E., Taylor, I.A. et al. (2017) A supramolecular assembly mediates lentiviral DNA integration. Science, 355, 93-95.

10. Bera, S., Pandey, K.K., Aihara, H. and Grandgenett, D.P. (2018) Differential assembly of Rous sarcoma virus tetrameric and octameric intasomes is regulated by the C-terminal domain and tail region of integrase. J. Biol. Chem., jbc.RA118.004768.

11. Passos, D.O., Li, M., Yang, R., Rebensburg, S.V., Ghirlando, R., Jeon, Y., Shkriabai, N., Kvaratskhelia, M., Craigie, R. and Lyumkis, D. (2017) Cryo-EM structures and atomic model of the HIV-1 strand transfer complex intasome. Science, 355, 89-92.

12. Yin, Z., Shi, K., Banerjee, S., Pandey, K.K., Bera, S., Grandgenett, D.P. and Aihara, H. (2016) Crystal structure of the Rous sarcoma virus intasome. Nature, 530, 362-366.

13. Hare, S., Gupta, S.S., Valkov, E., Engelman, A. and Cherepanov, P. (2010) Retroviral intasome assembly and inhibition of DNA strand transfer. Nature, 464, 232-236.

14. Mackler, R.M., Lopez, M.A. and Yoder, K.E. (2018) Assembly and Purification of Prototype Foamy Virus Intasomes. J Vis Exp.

15. Maertens, G.N., Hare, S. and Cherepanov, P. (2010) The mechanism of retroviral integration from X-ray structures of its key intermediates. Nature, 468, 326-329.

16. Li, M., Lin, S. and Craigie, R. (2016) Outer domains of integrase within retroviral intasomes are dispensible for catalysis of DNA integration. Protein Sci., 25, 472-478.

17. Maskell, D.P., Renault, L., Serrao, E., Lesbats, P., Matadeen, R., Hare, S., Lindemann, D., Engelman, A.N., Costa, A. and Cherepanov, P. (2015) Structural basis for retroviral integration into nucleosomes. Nature, 523, 366.

18. Wilson, M.D., Renault, L., Maskell, D.P., Ghoneim, M., Pye, V.E., Nans, A., Rueda, D.S., Cherepanov, P. and Costa, A. (2019) Retroviral integration into nucleosomes through DNA looping and sliding along the histone octamer. Nat Commun, 10, 4189.

19. Grandgenett, D.P. and Aihara, H. (2018) Oligomerization of Retrovirus Integrases. Subcell. Biochem., 88, 211-243.

20. Barski, M.S., Minnell, J.J., Hodakova, Z., Pye, V.E., Nans, A., Cherepanov, P. and Maertens, G.N. (2020) Cryo-EM structure of the deltaretroviral intasome in complex with the PP2A regulatory subunit B56gamma. Nat Commun, 11, 5043.

21. Bhatt, V., Shi, K., Salamango, D.J., Moeller, N.H., Pandey, K.K., Bera, S., Bohl, T.E., Kurniawan, F., Orellana, K., Zhang, W. et al. (2020) Structural basis of host protein hijacking in human T-cell leukemia virus integration. Nat Commun, 11, 3121. 
22. Passos, D.O., Li, M., Jozwik, I.K., Zhao, X.Z., Santos-Martins, D., Yang, R., Smith, S.J., Jeon, Y., Forli, S., Hughes, S.H. et al. (2020) Structural basis for strand-transfer inhibitor binding to HIV intasomes. Science, 367, 810-814.

23. Cook, N.J., Li, W., Berta, D., Badaoui, M., Ballandras-Colas, A., Nans, A., Kotecha, A., Rosta, E., Engelman, A.N. and Cherepanov, P. (2020) Structural basis of second-generation HIV integrase inhibitor action and viral resistance. Science, 367, 806-810.

24. Engelman, A.N. and Cherepanov, P. (2017) Retroviral intasomes arising. Curr. Opin. Struct. Biol., 47, 23-29.

25. Butler, S.L., Johnson, E.P. and Bushman, F.D. (2002) Human immunodeficiency virus cDNA metabolism: notable stability of two-long terminal repeat circles. Journal of Virology, 76, 3739-3747.

26. Lesbats, P., Engelman, A.N. and Cherepanov, P. (2016) Retroviral DNA Integration. Chem Rev, 116, $12730-12757$.

27. Yoder, K.E., Roddick, W., Hoellerbauer, P. and Fishel, R. (2011) XPB Mediated Retroviral cDNA Degradation Coincides with Entry to the Nucleus. Virology, 410, 291-298.

28. Jones, N.D., Jr, M.A.L., Hanne, J., Peake, M.B., Lee, J.-B., Fishel, R. and Yoder, K.E. (2016) Retroviral intasomes search for a target DNA by 1D diffusion which rarely results in integration. Nature Communications, 7, 11409.

29. Jones, N.D., Mackler, R.M., Lopez, M.A., Baltierra-Jasso, L.E., Altman, M.P., Senavirathne, G. and Yoder, K.E. (2019) Prototype foamy virus intasome aggregation is mediated by outer protein domains and prevented by protocatechuic acid. Scientific Reports, 9, 132.

30. Faschinger, A., Rouault, F., Sollner, J., Lukas, A., Salmons, B., Günzburg, W.H. and Indik, S. (2008) Mouse Mammary Tumor Virus Integration Site Selection in Human and Mouse Genomes. Journal of Virology, 82, 1360-1367.

31. Hutchinson, J.N. and Muller, W.J. (2000) Transgenic mouse models of human breast cancer. Oncogene, 19, 6130-6137.

32. Maeda, N., Fan, H. and Yoshikai, Y. (2008) Oncogenesis by retroviruses: old and new paradigms. Reviews in Medical Virology, 18, 387-405.

33. Ross, S.R. (2010) Mouse mammary tumor virus molecular biology and oncogenesis. Viruses, 2 , 2000-2012.

34. Theodorou, V., Kimm, M.A., Boer, M., Wessels, L., Theelen, W., Jonkers, J. and Hilkens, J. (2007) MMTV insertional mutagenesis identifies genes, gene families and pathways involved in mammary cancer. Nat. Genet., 39, 759-769.

35. De Rijck, J., de Kogel, C., Demeulemeester, J., Vets, S., El Ashkar, S., Malani, N., Bushman, F.D., Landuyt, B., Husson, S.J., Busschots, K. et al. (2013) The BET family of proteins targets moloney murine leukemia virus integration near transcription start sites. Cell Rep, 5, 886-894.

36. Sharma, A., Larue, R.C., Plumb, M.R., Malani, N., Male, F., Slaughter, A., Kessl, J.J., Shkriabai, N., Coward, E., Aiyer, S.S. et al. (2013) BET proteins promote efficient murine leukemia virus integration at transcription start sites. Proc. Natl. Acad. Sci. U.S.A., 110, 12036-12041.

37. Shun, M.-C., Raghavendra, N.K., Vandegraaff, N., Daigle, J.E., Hughes, S., Kellam, P., Cherepanov, P. and Engelman, A. (2007) LEDGF/p75 functions downstream from preintegration complex formation to effect gene-specific HIV-1 integration. Genes Dev, 21, 1767-1778.

38. de Jong, J., Akhtar, W., Badhai, J., Rust, A.G., Rad, R., Hilkens, J., Berns, A., van Lohuizen, M., Wessels, L.F.A. and de Ridder, J. (2014) Chromatin landscapes of retroviral and transposon integration profiles. PLoS Genet., 10, e1004250.

39. Serrao, E., Ballandras-Colas, A., Cherepanov, P., Maertens, G.N. and Engelman, A.N. (2015) Key determinants of target DNA recognition by retroviral intasomes. Retrovirology, 12, 39.

40. McKee, C.J., Kessl, J.J., Shkriabai, N., Dar, M.J., Engelman, A. and Kvaratskhelia, M. (2008) Dynamic modulation of HIV-1 integrase structure and function by cellular lens epithelium-derived growth factor (LEDGF) protein. J. Biol. Chem., 283, 31802-31812.

41. Scott, D.W. (1979) On optimal and data-based histograms. Biometrika, 66, 605-610.

42. Sturges, H.A. (1926) The Choice of a Class Interval. Journal of the American Statistical Association, 21, 65-66.

43. Messer, R.K., Jr, M.A.L., Senavirathne, G. and Yoder, K.E. (2019) Expression and Purification of Nuclease-Free Oxygen Scavenger Protocatechuate 3,4-Dioxygenase. JoVE (Journal of Visualized Experiments), e59599. 
44. Senavirathne, G., Lopez, M.A., Messer, R., Fishel, R. and Yoder, K.E. (2018) Expression and purification of nuclease-free protocatechuate 3,4-dioxygenase for prolonged single-molecule fluorescence imaging. Analytical Biochemistry, 556, 78-84.

45. Vallotton, P. and Olivier, S. (2013) Tri-track: free software for large-scale particle tracking. Microsc Microanal, 19, 451-460.

46. Hazuda, D.J., Felock, P.J., Hastings, J.C., Pramanik, B. and Wolfe, A.L. (1997) Differential divalent cation requirements uncouple the assembly and catalytic reactions of human immunodeficiency virus type 1 integrase. Journal of Virology, 71, 7005-7011.

47. Mackler, R.M., Lopez, M.A., Osterhage, M.J. and Yoder, K.E. (2018) Prototype foamy virus integrase is promiscuous for target choice. Biochemical and Biophysical Research Communications, 503, 1241-1246.

48. Wolfe, A.L., Felock, P.J., Hastings, J.C., Blau, C.U. and Hazuda, D.J. (1996) The role of manganese in promoting multimerization and assembly of human immunodeficiency virus type 1 integrase as a catalytically active complex on immobilized long terminal repeat substrates. Journal of Virology, 70, 1424-1432.

49. Gao, K., Wong, S. and Bushman, F. (2004) Metal Binding by the D,DX35E Motif of Human Immunodeficiency Virus Type 1 Integrase: Selective Rescue of Cys Substitutions by Mn2+ In Vitro. Journal of Virology, 78, 6715-6722.

50. Li, M., Jurado, K.A., Lin, S., Engelman, A. and Craigie, R. (2014) Engineered hyperactive integrase for concerted HIV-1 DNA integration. PLOS ONE, 9, e105078.

51. Bulos, B.A. and Sacktor, B. (1979) Determination of the concentration of free $\mathrm{Ca} 2+$ in the presence of magnesium (or manganese) and chelating effectors of the NAD+-linked isocitrate dehydrogenase. Anal Biochem, 95, 62-72.

52. Keller, F., Emde, C. and Schwarz, A. (1988) Exponential function for calculating saturable enzyme kinetics. Clinical chemistry, 34, 2486-2489.

53. Aitken, C.E., Marshall, R.A. and Puglisi, J.D. (2008) An Oxygen Scavenging System for Improvement of Dye Stability in Single-Molecule Fluorescence Experiments. Biophys J, 94, 18261835.

54. Marini, I., Moschini, R., Del Corso, A. and Mura, U. (2005) Chaperone-like features of bovine serum albumin: a comparison with alpha-crystallin. Cellular and molecular life sciences : CMLS, 62, 30923099.

55. Chang, B.S. and Mahoney, R.R. (1995) Enzyme thermostabilization by bovine serum albumin and other proteins: evidence for hydrophobic interactions. Biotechnology and applied biochemistry, 22, 203-214.

56. Bagchi, B., Blainey, P.C. and Xie, X.S. (2008) Diffusion constant of a nonspecifically bound protein undergoing curvilinear motion along DNA. The journal of physical chemistry. B, 112, 6282-6284.

57. Blainey, P.C., Luo, G., Kou, S.C., Mangel, W.F., Verdine, G.L., Bagchi, B. and Xie, X.S. (2009) Nonspecifically bound proteins spin while diffusing along DNA. Nat Struct Mol Biol, 16, 1224-1229.

58. Araujo, A.R., Ribeiro, A.J., Fernandes, P.A. and Ramos, M.J. (2014) Catalytic Mechanism of Retroviral Integrase for the Strand Transfer Reaction Explored by QM/MM Calculations. Journal of chemical theory and computation, 10, 5458-5466.

59. Allingham, J.S. and Haniford, D.B. (2002) Mechanisms of metal ion action in Tn10 transposition. J. Mol. Biol., 319, 53-65.

60. Engelman, A. and Craigie, R. (1995) Efficient magnesium-dependent human immunodeficiency virus type 1 integrase activity. Journal of Virology, 69, 5908-5911.

61. Skinner, L.M., Sudol, M., Harper, A.L. and Katzman, M. (2001) Nucleophile selection for the endonuclease activities of human, ovine, and avian retroviral integrases. J. Biol. Chem., 276, 114124.

62. Yang, W., Lee, J.Y. and Nowotny, M. (2006) Making and Breaking Nucleic Acids: Two-Mg2+-Ion Catalysis and Substrate Specificity. Molecular Cell, 22, 5-13.

63. Grawenhoff, J. and Engelman, A.N. (2017) Retroviral integrase protein and intasome nucleoprotein complex structures. World J Biol Chem, 8, 32-44.

64. Berg, O.G., Winter, R.B. and Von Hippel, P.H. (1981) Diffusion-driven mechanisms of protein translocation on nucleic acids. 1. Models and theory. Biochemistry, 20, 6929-6948.

65. Gorman, J. and Greene, E.C. (2008) Visualizing one-dimensional diffusion of proteins along DNA. Nat. Struct. Mol. Biol., 15, 768-774. 
66. Gowers, D.M., Wilson, G.G. and Halford, S.E. (2005) Measurement of the contributions of 1D and 3D pathways to the translocation of a protein along DNA. Proc. Natl. Acad. Sci. U.S.A., 102, 1588315888.

67. Mirny, L., Slutsky, M., Wunderlich, Z., Tafvizi, A., Leith, J. and Kosmrlj, A. (2009) How a protein searches for its site on DNA: the mechanism of facilitated diffusion. J. Phys. A: Math. Theor., 42, 434013.

68. Mondal, A. and Bhattacherjee, A. (2015) Searching target sites on DNA by proteins: Role of DNA dynamics under confinement. Nucleic Acids Research, 43, 9176-9186.

69. Shimamoto, N. (1999) One-dimensional Diffusion of Proteins along DNA its biological and chemical significance revealed by single-molecule measurements. J. Biol. Chem., 274, 15293-15296.

70. Shvets, A.A., Kochugaeva, M.P. and Kolomeisky, A.B. (2018) Mechanisms of Protein Search for Targets on DNA: Theoretical Insights. Molecules, 23.

71. Dikić, J., Menges, C., Clarke, S., Kokkinidis, M., Pingoud, A., Wende, W. and Desbiolles, P. (2012) The rotation-coupled sliding of EcoRV. Nucleic Acids Research, 40, 4064-4070.

72. Bonnet, I., Biebricher, A., Porté, P.-L., Loverdo, C., Bénichou, O., Voituriez, R., Escudé, C., Wende, W., Pingoud, A. and Desbiolles, P. (2008) Sliding and jumping of single EcoRV restriction enzymes on non-cognate DNA. Nucleic Acids Research, 36, 4118-4127.

73. Miller, M.D., Bor, Y.C. and Bushman, F. (1995) Target DNA capture by HIV-1 integration complexes. Curr. Biol., 5, 1047-1056.

74. Cherepanov, P. (2007) LEDGF/p75 interacts with divergent lentiviral integrases and modulates their enzymatic activity in vitro. Nucleic Acids Research, 35, 113-124.

75. Mackler, R.M., Jones, N.D., Gardner, A.M., Lopez, M.A., Howard, C.J., Fishel, R. and Yoder, K.E. (2019) Nucleosome DNA unwrapping does not affect prototype foamy virus integration efficiency or site selection. PLOS ONE, 14, e0212764.

76. Nowrouzi, A., Dittrich, M., Klanke, C., Heinkelein, M., Rammling, M., Dandekar, T., von Kalle, C. and Rethwilm, A. (2006) Genome-wide mapping of foamy virus vector integrations into a human cell line. J. Gen. Virol., 87, 1339-1347.

77. Francis, A.C., Marin, M., Singh, P.K., Achuthan, V., Prellberg, M.J., Palermino-Rowland, K., Lan, S., Tedbury, P.R., Sarafianos, S.G., Engelman, A.N. et al. (2020) HIV-1 replication complexes accumulate in nuclear speckles and integrate into speckle-associated genomic domains. Nature communications, 11, 3505.

\section{FIGURE LEGENDS}

Figure 1. MMTV intasomes have different integration efficiencies in the presence of manganese or magnesium. MMTV intasome integration to a SC plasmid was performed with increasing concentrations of (A) $\mathrm{MgCl}_{2}$, (B) $\mathrm{MnCl}_{2}$, (C) $\mathrm{MgSO}_{4}$, and (D) $\mathrm{NaCl}$. Integration products were separated by agarose gel electrophoresis and quantified by the Cy5 fluorescent signal in each lane (fmol). Half-site integration (HSI) products where only one vDNA has been joined to the plasmid have the mobility of a relaxed circle. A single concerted integration product $\left(\mathrm{Cl}^{1}\right)$ has the mobility of a linear plasmid. Additional $\mathrm{Cl}$ events $\left(\mathrm{Cl}^{2}\right)$ result in a smear between $\mathrm{Cl}^{1}$ and unreacted vDNA. Autointegration (Al) of vDNA to vDNA has slower mobility than unreacted vDNA. All reactions include $1 \mathrm{mM} \mathrm{CaCl}_{2}$ which is present during intasome assembly and purification. MMTV intasomes are not active in the absence of magnesium or manganese divalent ions. Increasing concentrations of $\mathrm{MgCl}_{2}$ or $\mathrm{MgSO}_{4}$ lead to increasing total $\mathrm{Cl}\left(\mathrm{Cl}=\mathrm{Cl}^{1}+\mathrm{Cl}^{2}\right)$. Al products were only apparent at the highest concentration of $\mathrm{MgCl}_{2}$. In contrast, MMTV intasome $\mathrm{Cl}$ was equivalent at all concentrations of $\mathrm{MnCl}_{2}$ assayed, while Al products increased with increasing concentrations of $\mathrm{MnCl}_{2}$. $\mathrm{HSI}$ products were unaffected by the increasing concentrations of divalent ions. MMTV intasomes were also assayed with a titration of $\mathrm{NaCl}$ in the presence of $20 \mathrm{mM} \mathrm{MgSO}_{4}$. MMTV Cl products peaked in the 
physiologically relevant range of $100-150 \mathrm{mM} \mathrm{NaCl}$. Fewer $\mathrm{Cl}$ products were observed at $>150 \mathrm{mM} \mathrm{NaCl}$. MMTV integration efficiency appeared to be reduced at $50 \mathrm{mM} \mathrm{NaCl}$, a concentration less than physiological, but was not statistically significant. Error bars indicate the standard deviation of at least 3 independent experiments performed with at least 2 independent MMTV intasome preparations.

Figure 2. Time course and catalytic rate of MMTV intasomes. (A) MMTV intasomes were evaluated for integration to a SC plasmid for up to $3 \mathrm{~h}$. Integration products were separated by agarose gel electrophoresis and quantified by the Cy5 fluorescent signal in each lane (fmol). Based on the accumulation of $\mathrm{Cy} 5 \mathrm{Cl}$ products, MMTV intasomes retained activity for at least $80 \mathrm{~min}$. (B) The initial rate of reaction was estimated based on velocity vs substrate concentration. Increasing SC plasmid concentrations were converted to $\mathrm{nM}$ sites $(0.25,0.3,0.35,0.4,0.45,0.5,1,3$ and $6 \mathrm{nM})$ considering the number of possible MMTV intasome binding sites in the $3 \mathrm{~kb}$ target plasmid. The MMTV intasome minimal recognition site is 6 $\mathrm{bp}$, with a likely higher limit of $12 \mathrm{bp}$. This range of site size yields a $K_{m \cdot a p p}$ range from 34.5 to $69.0 \mathrm{nM}$. The calculated $k_{\text {cat app }}$ for MMTV intasomes is $0.01 \mathrm{~min}^{-1}$. Error bars indicate the standard deviation of at least 3 independent experiments performed with at least 2 independent MMTV intasome preparations.

Figure 3. MMTV intasome aggregation. MMTV intasomes were incubated for $1 \mathrm{~h}$ at $37^{\circ} \mathrm{C}$ in integration reaction buffer with indicated concentrations of components. All aggregation reactions include $1 \mathrm{mM} \mathrm{CaCl} 2$ carried over from the purification buffer. Aggregates were pelleted by centrifugation and analyzed by denaturing PAGE stained with Coomassie blue. (A) The percentage of precipitated MMTV IN (\% Aggregation) is relative to the control lane (lane 1). Increasing concentrations of $\mathrm{MgSO}_{4}$ led to decreased aggregation of MMTV intasomes. Addition of $10 \mathrm{mM} \mathrm{CaCl}_{2}$ (final concentration $11 \mathrm{mM} \mathrm{CaCl}$ ) reduced aggregation, similar to the highest concentrations of $\mathrm{MgSO}_{4}$. Addition of acetylated BSA was the most effective at preventing MMTV intasome aggregation. (B) MMTV intasome aggregation in the presence of $20 \mathrm{mM} \mathrm{MgSO}_{4}$ was assayed with a titration of $\mathrm{NaCl}$. NaCl concentrations $>100 \mathrm{mM}$ also led to a decrease of MMTV intasome aggregation. The difference in aggregation between $100 \mathrm{mM}$ and 200 or $300 \mathrm{mM} \mathrm{NaCl}$ was significant $(p<0.05)$, but there was no significant difference between aggregation in 150 , 200, or 300 $\mathrm{mM} \mathrm{NaCl}$. Error bars indicate the standard deviation of at least 3 independent experiments performed with at least 2 independent MMTV intasome preparations.

Figure 4. MMTV intasome stand transfer kinetics and search dynamics. (A) The time between the two strand transfers $(\tau \mathrm{ST})$ of MMTV vDNA was determined by single-molecule magnetic tweezers. A linear DNA was attached at multiple points to a surface and a paramagnetic bead. Magnets above the microscope stage introduced negative supercoils to the DNA, effectively reducing the apparent height of the bead. The beads were tracked in the $x-, y-$, and $z$-axes. The first strand transfer event introduces a nick in the target DNA releasing the supercoils, and changing the z-axis position (blue triangle). The second strand transfer introduces another nick and releases the bead, seen as changes in $x-, y-$, and z-axes. A representative 
integration event is shown. The $\tau \mathrm{st}$ is the time between the first and second strand transfer events. (B) The $\tau \mathrm{ST}$ measured for 41 independent integration events was used to construct a histogram. For MMTV intasomes $\tau_{\mathrm{ST}}$ is $1.31 \pm 0.12 \mathrm{~s}$. (C) Fluorescently labeled MMTV intasomes moving on linear DNA were tracked by TIRF microscopy. A $24 \mathrm{~kb}$ linear DNA was attached at both ends to a flow cell surface. 50-100 pM fluorescently labeled MMTV intasomes were added to the flow cell. A representative kymograph of a single MMTV intasome in association with target DNA is shown; the $x$ axis of the trace is time and the $y$ axis is the length of the target DNA. (D) The lifetime ( $\mathrm{ONN}$ ) of MMTV intasomes in association with target DNA was measured at multiple concentrations of $\mathrm{NaCl}$. Increasing $\mathrm{NaCl}$ concentrations had an inverse relationship with the $\tau$ on of the intasomes. (E) Diffusion coefficients of MMTV intasomes were measured at multiple $\mathrm{NaCl}$ concentrations. The diffusion coefficients were similar, indicating a random walk search of $\sim 2.5 \mathrm{~kb}$ at $110 \mathrm{mM} \mathrm{NaCl}$. Error bars indicate the standard deviation of at least 3 independent experiments performed with at least 2 independent MMTV intasome preparations.

Figure 5. MMTV intasomes are prone to aggregation in the presence of target DNA. (A) When 2 nM MMTV intasomes were injected in the flow cell they aggregated on the stretched DNA molecules. The images suggest recruitment and accumulation of additional MMTV intasomes binding the target DNA molecules over time. (B) MMTV intasome aggregation was assayed in the absence or presence of $3 \mathrm{~kb}$ linear DNA. Wild type and catalytically inactive IN(D122N) intasomes were incubated for $1 \mathrm{~h}$ at $37^{\circ} \mathrm{C}$ in the presence of $110 \mathrm{mM} \mathrm{NaCl}$. Aggregates were pelleted by centrifugation and analyzed by denaturing PAGE. Both wild type and mutant intasomes displayed increased aggregation when linear DNA was present, indicating that aggregation does not require catalysis. The graph represents the mean of three independent experiments performed with at least two independent MMTV intasome purifications. 


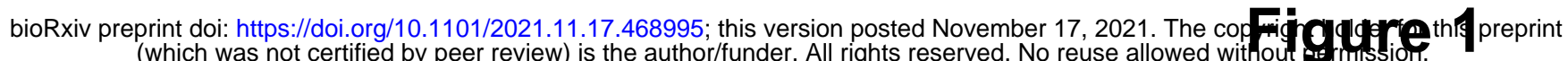

A
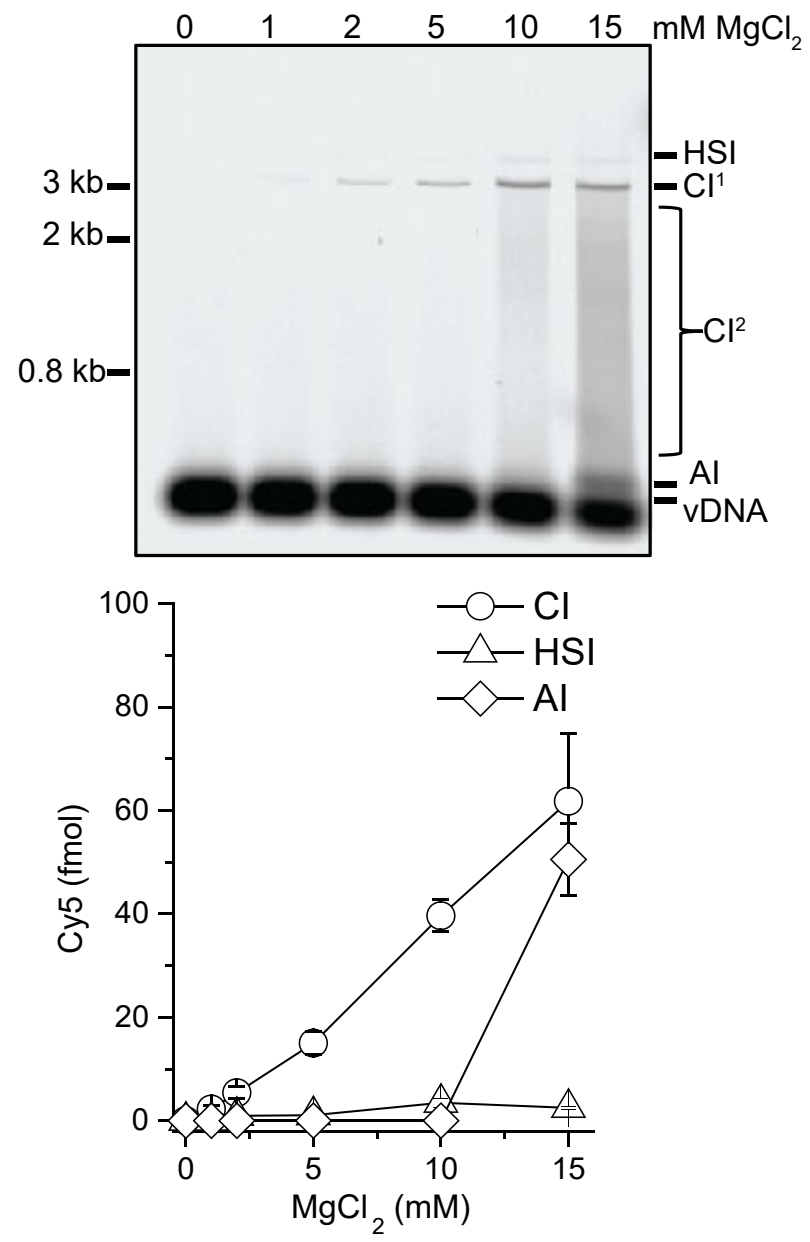

C
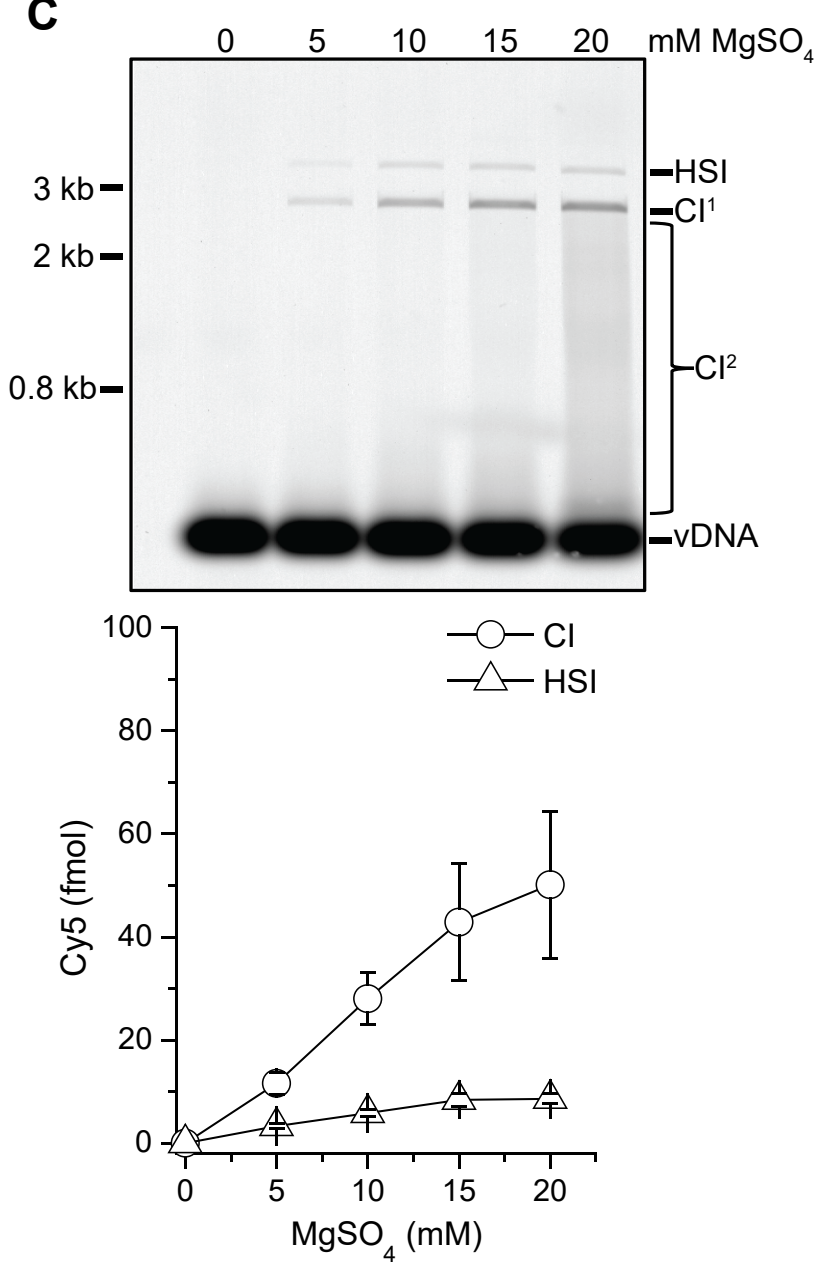

B

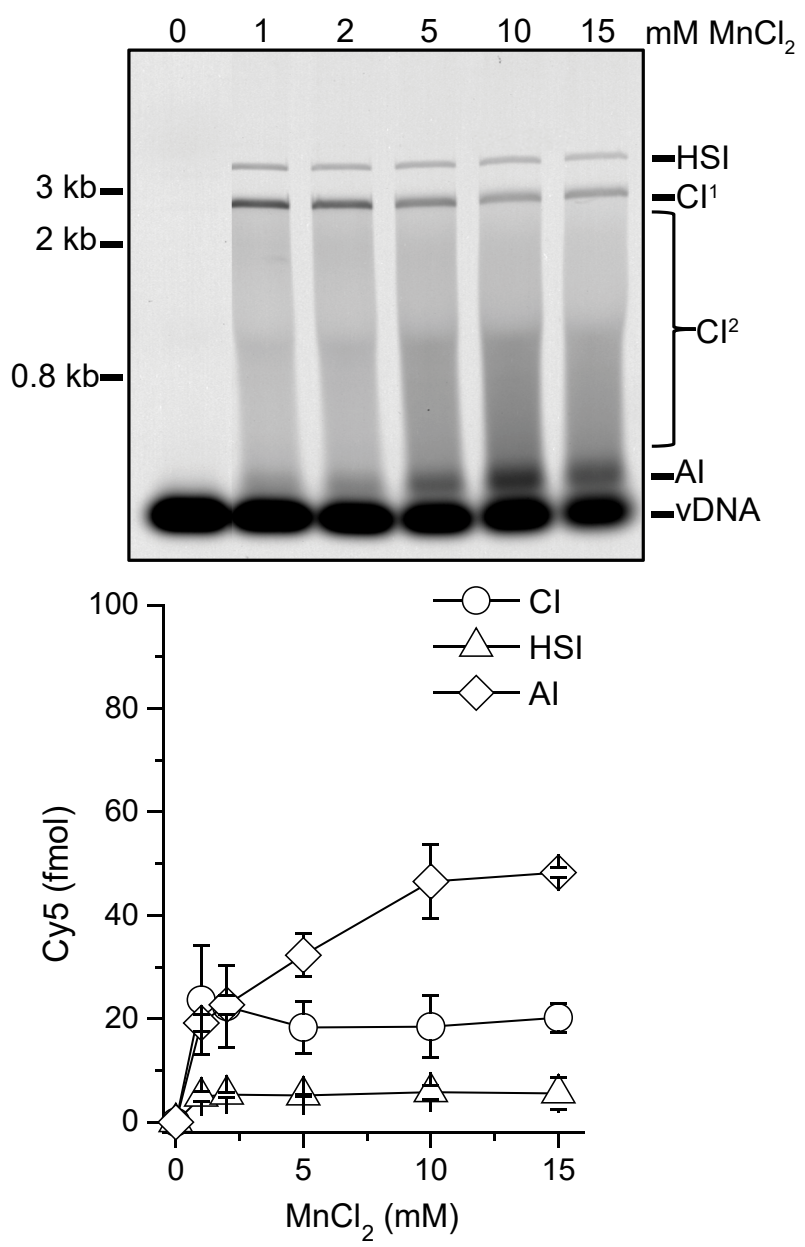

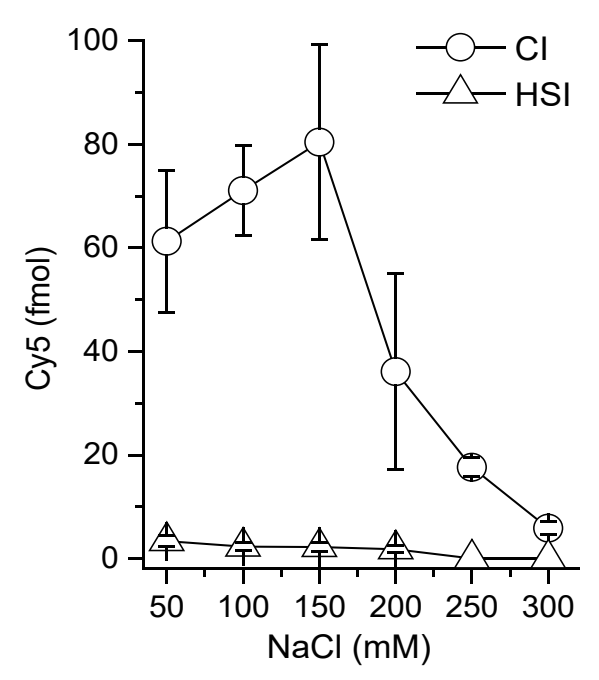


bioRxiv preprint doi: https://doi.org/10.1101/2021.11.17.468995; this version posted November 17, 2021. The copyright holder for this preprint

(which was not certified by peer review) is the author/funder. All rights reserved. No reuse allowed with gut permission?

A
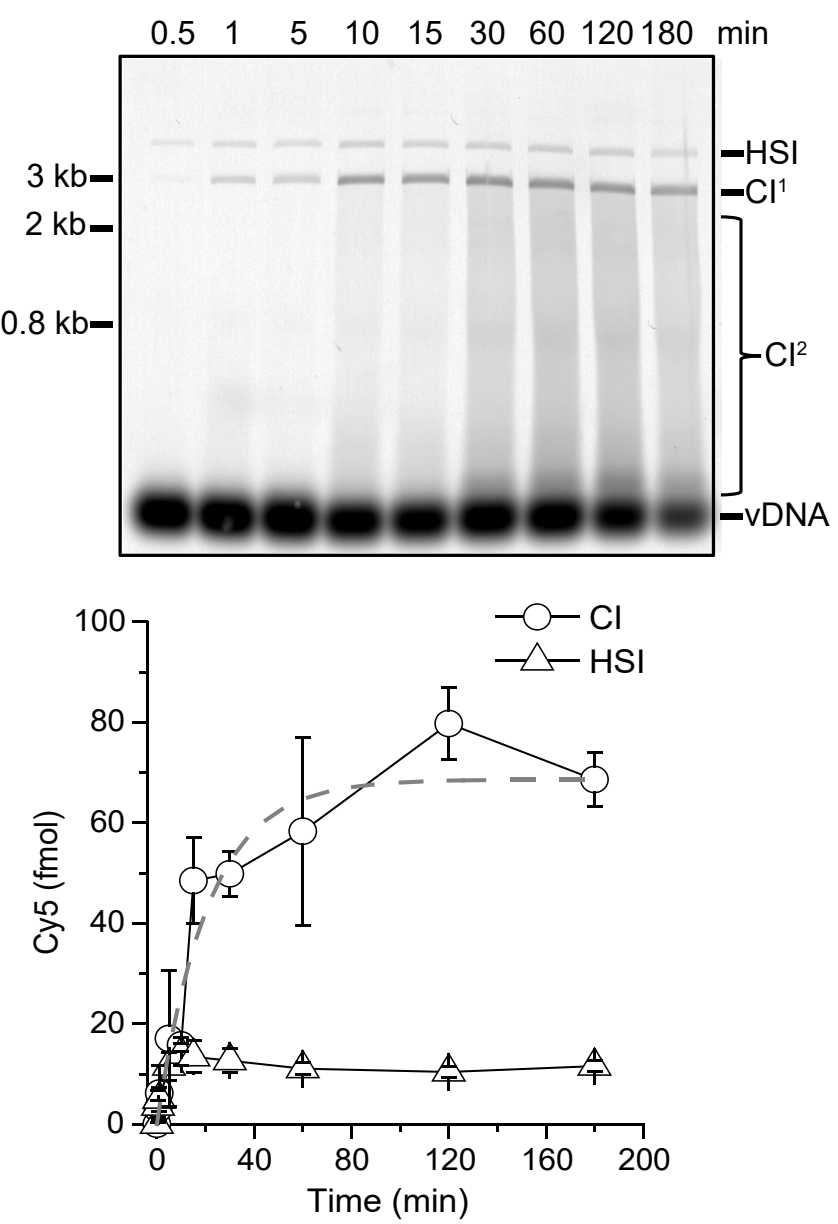

B

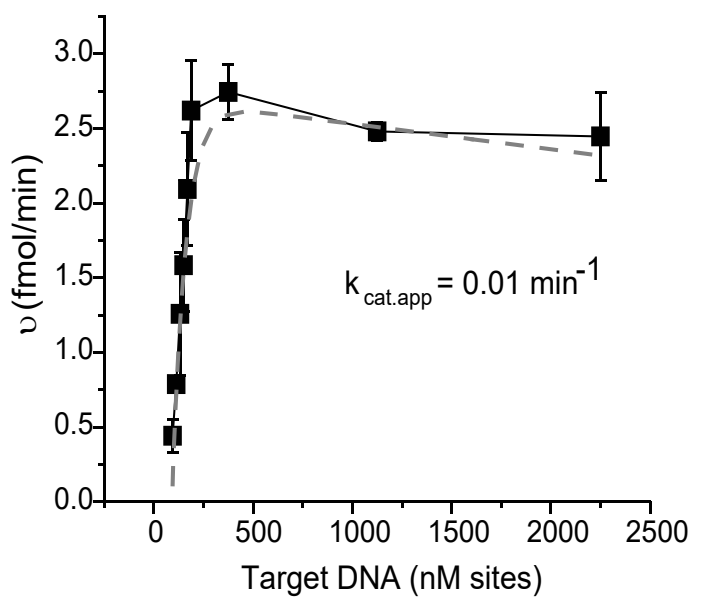



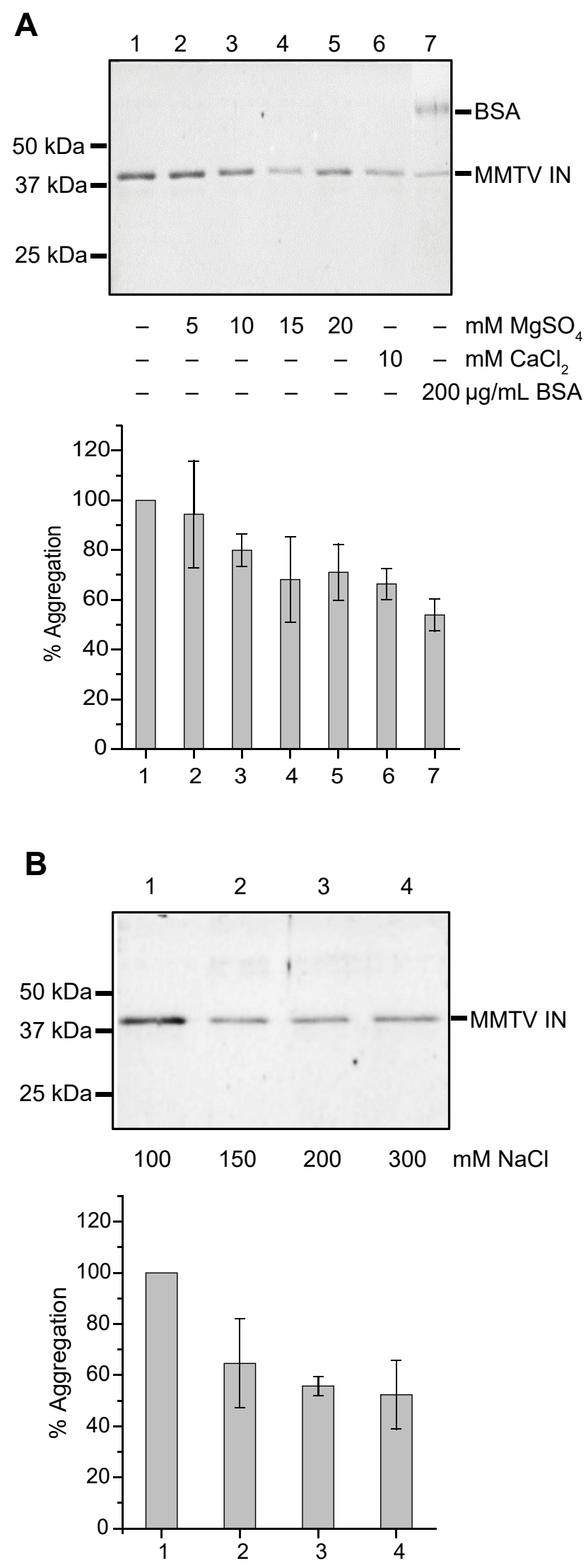
A

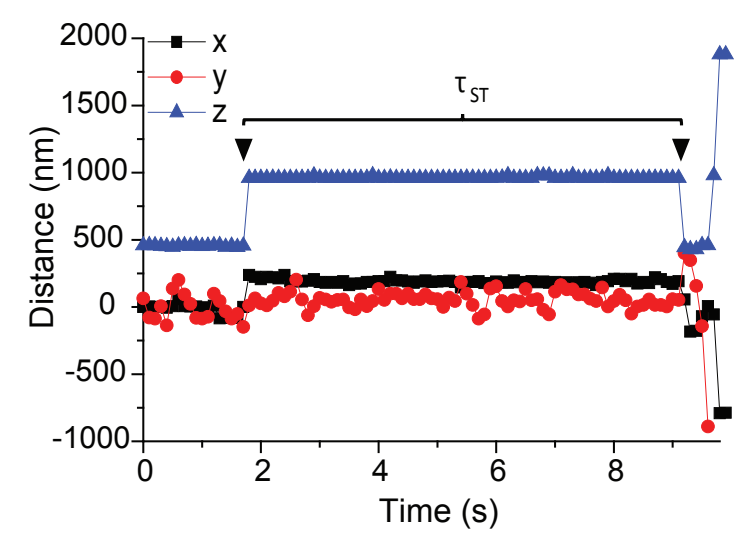

B

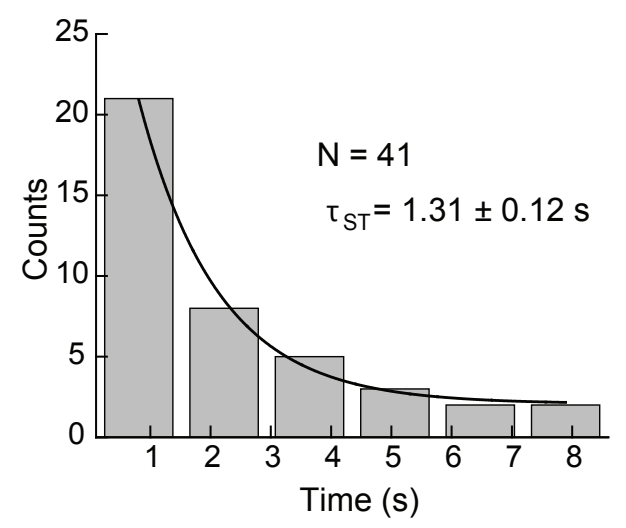

C

$3.5 \mu \mathrm{m}$

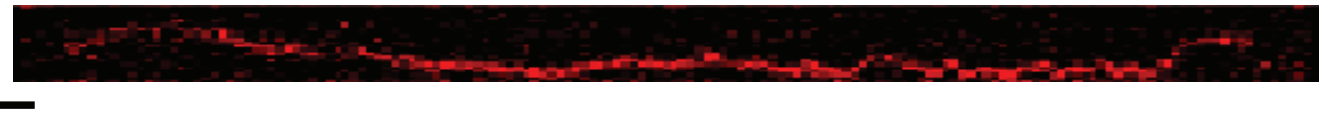

$10 \mathrm{~s}$

D

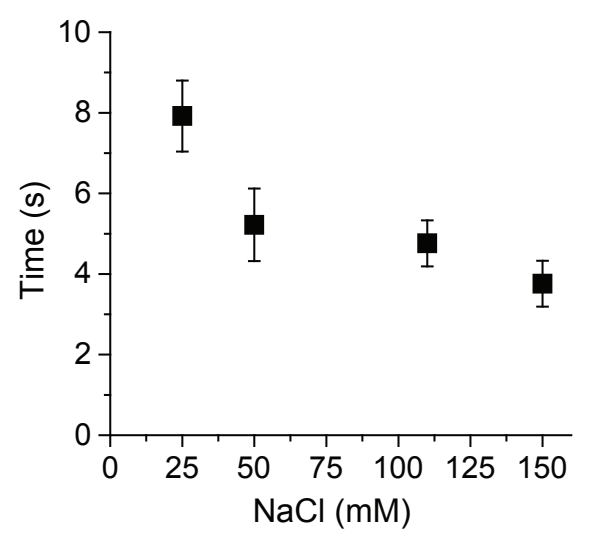

E

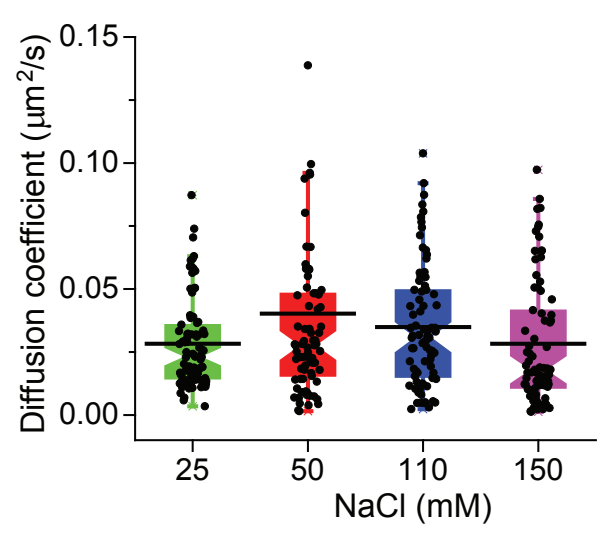


A

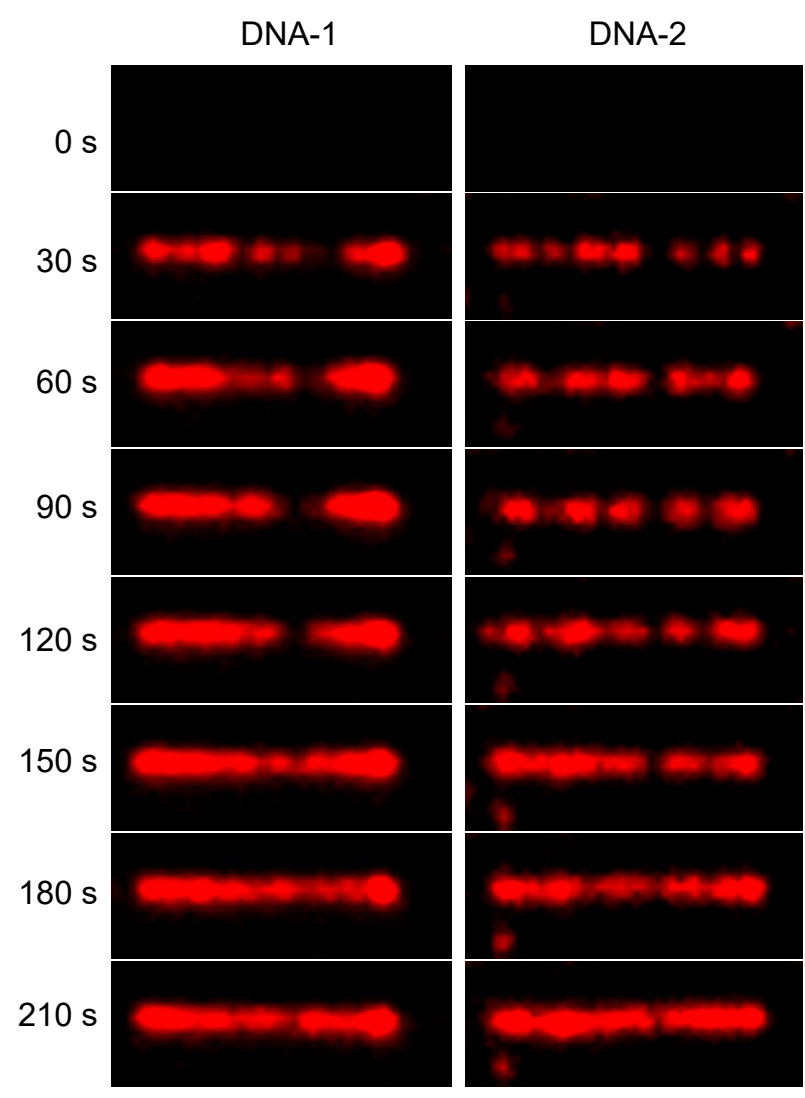

B
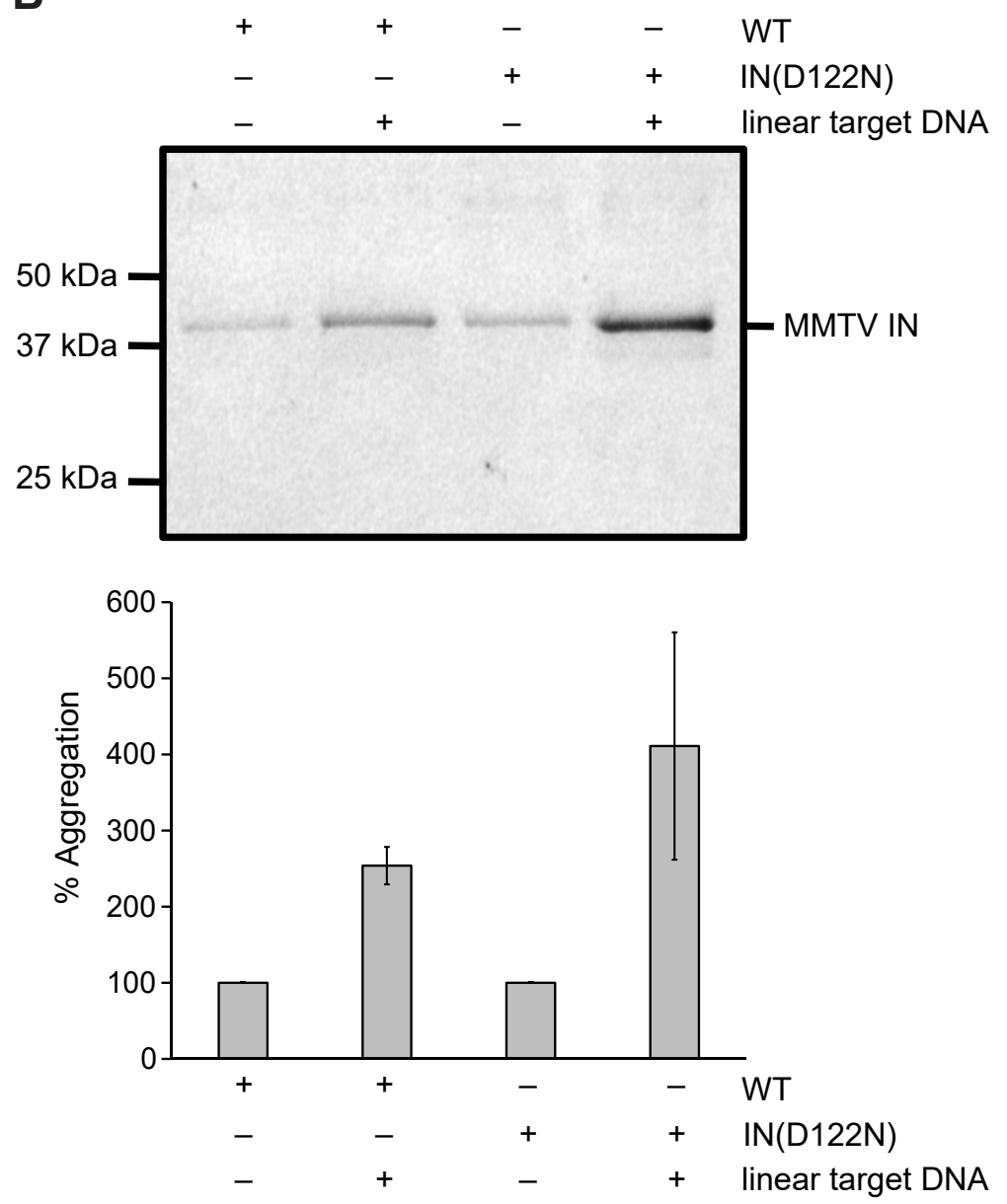